\title{
The Impacts of Learning Analytics on Primary Level Mathematics Curriculum
}

\author{
Izzat Syahir Mohd Ramli*, Siti Mistima Maat, Fariza Khalid \\ Faculty of Education, Universiti Kebangsaan Malaysia, Malaysia
}

Received January 22, 2020; Revised April 1, 2020; Accepted April 21, 2020

Copyright $\odot 2020$ by authors, all rights reserved. Authors agree that this article remains permanently open access under the terms of the Creative Commons Attribution License 4.0 International License

\begin{abstract}
Mathematics is important for the academic life of students. The Fourth Industrial Revolution has transformed the Mathematics education landscape and how students learn mathematics. As such, students today use ICT as a tool to help them understand mathematics in easy way. This is because ICT has an increasing influence on the way students interact, learn and live. The advancement of technology has triggered a revolution in data generation by the devices used. Hence, learning analytics (LA) is very useful and significant in today's teaching and learning. LA is a fast growing area in academia and helps teacher on collecting, analysis, processing and visualization of data to help them understand students in deep. This study aimed at identifying the impact of LA in mathematics curriculum. Hence, this article was drawn from previous works of literature to create an overview of the issue pertaining to LA on primary level mathematics curriculum. The application of LA in Mathematics is effective in helping teachers to understand students' potential thus improving the overall quality of the teaching and learning process. The application of technology within this approach will enable teachers to build an effective learning process. In future, the application of the LA and GBL approaches in Mathematics is an approach that can be explored in-depth to assess its effectiveness to improve students' mastery in Mathematics.
\end{abstract}

Keywords Mathematics, Learning Analytics,
Technology

\section{Introduction}

The development of technology and multimedia in today's daily life has slightly affected the way in teaching and learning Mathematics in schools. Technological application especially the use of multimedia courseware has become common in today's education, stimulating innovative approaches in teaching and learning Mathematics. Moreover, today's students are also the digital generation. They are also the generation who are more likely to choose digital tools as learning materials and play learning [19]. With the development of this technology, teaching and learning of Mathematics in schools has also been affected. This situation is due to the changes in the current Mathematics curriculum which emphasizes the application of technology in the teaching and learning of Mathematics in creating a conducive and fun learning environment.

However, the development of information technology has sparked a revolution in the production of data by technological. But, the richness of data are not managed and analysed properly to help provide meaningful and useful information for users [7]. Hence, learning analytics (LA) is significant in the field of education because it helps teachers interpret the data obtained from students via technology. LA focuses on collecting, cleaning, processing, visualization and analysing teaching and learning related data [18]. LA in Mathematics allows teachers to interpret the data to predict both students' achievement and the risk of dropouts. This enables teachers to visualize the mathematics learning process with the benefit of data in helping to improve the effectiveness of the mathematics teaching and learning process. Moreover, it also provides valuable information to teachers to improve their quality of teaching [8]. As a result, teachers will understand students learning environment better via LA.

As such, teachers should possess productive roles and responsibilities to create a dynamic learning environment. Reports show that academics in Europe and the United State apply LA to help students succeed in classroom learning [9]. Therefore, the application of technology and LA is very much needed by today's teachers because the task load of teachers is currently constrained by teachers to effectively monitor pupils' behaviour and learning. So that, teachers should be more creative and innovative with the design and implementation of lessons in classrooms. 


\section{Materials and Methods}

This study aimed at identifying the impact of LA in Mathematics curriculum. Researcher uses the PRISMA method which includes resources from Scopus and Web of Science that used to run the systematic review, determining eligibility and exclusion criteria, and the systematic review process. Several eligibility and exclusion are specified. First selection criteria are the type of literature selected, only journal articles with empirical data selected. This means that review journal articles, book series, chapters in books and conference papers are excluded. Second, selection criteria are an article journal written in English. Journal articles written besides English are excluded. This is to avoid any problems and mistakes in translating and understanding the article journals well.

\section{Results and Discussion}

The finding show the impact of LA in Mathematics curriculum and how to implement LA in Mathematics. The results and discussion as below:

\subsection{Learning Analytics (LA) in Mathematics Education}

Mathematics curriculum today stresses that students should not be merely judged based on their grades. Nevertheless, there should be a holistic and in-depth approach when it comes to assessing students throughout the process of learning and teaching. Besides that, the transformation and development of the Mathematics curriculum have also changed the goals of teaching and learning Mathematics. The current curriculum emphasises the application of technology in the process of teaching and learning Mathematics. It is done to create a conducive, fun learning environment, to promote higher learning and support the acquisition of basic digital skills among students [13] at the primary level.

According to [16], the LA approach is divided into two namely visual analytic and automatic actuators. Visual analytic approach aims to provide students with visualization as self-reflection and provide teachers with visual information so that teachers can interpret and make informed decisions in assisting the teaching and learning process with the help of visual information. Next, automatic actuators approach is intended to implement automated actuators such as recommendations or expectations that consider different variables in the teaching and learning process [16]. This automated actor does not require intervention of a teacher or a student but is usually restricted to meaningful specific clues.

In the teaching and learning of Mathematics, LA helps improve students' learning skills [11] through its ability to anticipate their achievements [7]. As a result, teachers will be able to take proactive steps to improve pupils' understanding when it comes to learning. Moreover, the expected results will also encourage students who are at risk of dropping out or performing poorly in class to improvise their learning strategies [6]. It will also enable teachers to review all the teaching methods that have been implemented. Besides that, students will also have the opportunity to evaluate the effectiveness of the lessons. As a result, the teaching and learning process will always evolve to ensure learning the objectives are achieved and students continue to exhibit progress in Mathematics. Therefore, it reduces the risk of students giving up on Mathematics.

Besides, LA is widely applied in Mathematics to improve the quality of teaching and learning. In general, there was an improvement in the quality of teaching materials, teachers' ability to identify students' academic progress and students' attitude and behaviour towards Mathematics as a subject. These factors had simultaneously improved the quality of teaching. LA in Mathematics enables teachers to leverage on the wealth of information which will then provide accurate feedback to students and valuable information for teachers in order to improve the quality of teaching [17] and develop a better understanding of the learning environment [18].

\subsection{Implement LA in Mathematics}

We already know the potential of applying LA in Mathematics. But how to implement LA in Mathematics? The findings of this previous study provide the impression that in order to implement LA elements, a new learning material needs to be developed. However, there are also past reviewers who have only improved existing learning materials by implementing LA as an innovation. Table 1 below summarizes the purpose of the study and the category of learning materials used. 
Table 1. Summary purpose of the study and the category of learning materials used

\begin{tabular}{cccc}
\hline Researcher & Learning Materials & Material Category & Purpose \\
\hline Romero et al. (2012) & Cognitive tutors & New Material & Predict student achievement \\
\hline Kim et al. (2016) & Cognitive tutors & Improvement Material & Improving the quality of teaching \\
\hline Roman et al. (2018) & Cognitive tutors & New Material & Predict student achievement \\
\hline Molenaar \& Campen (2018) & Cognitive tutors & Improvement Material & Improving the quality of teaching \\
\hline Tomkin, West, \& Herman (2018) & Cognitive tutors & New Material & Predict student achievement \\
\hline
\end{tabular}

Note: Cognitive tutors (special software materials for research purposes)

The findings from this research report indicate that the construction of new learning materials with the application of LA is used to predict pupils' progress in learning especially predictions regarding student achievement. In addition, learning materials improved with the implementation of LA are used to improve the quality of learning. This enables the teacher to obtain the data resulting from the application of the learning materials developed for analysis and help the teacher utilize all the data obtained in improving the quality of teaching and predict student's performance.

\subsection{Applying Game-based Learning (GBL) Approach with LA in Mathematics}

To implement LA in Mathematics, teacher should construct new learning material or improved learning material. However, game-based learning (GBL) approach also can be use in implement LA. GBL is seen as one of learning medium that can attract students to master's in mathematics. It is also more effective with clearly defined learning objectives that work in tandem with a curriculum that emphasises student-centred learning. As a result, the application of GBL has succeeded in improving students confidence and increasing their interest for learning [5]. This will enhance students' competency and ability as well as help improve students' achievement in Mathematics.

Hence, [3] asserted that GBL has the potential to improve students' progress in Mathematics. They further justified their claims by saying that students will apply basic Mathematical, reading and problem-solving skills while playing to ensure that the given assignment is accomplished. Moreover, GBL also has the potential to cultivate a positive attitude and behaviour among students. This is because a well-designed game-based learning approach can draw in students into activities that create a meaningful learning environment. As a result, students will learn to collaborate during the process of learning [2] to achieve set learning objectives. Additionally, a healthy competition during lessons will create excitement among students. They get to learn while playing. This will eventually shape a positive attitude towards the learning of Mathematics.

The benefits of GBL should not be disregarded. The combination of GBL and LA can give a more positive effect on the process of teaching and learning Mathematics. This will help elevate students' mastery of the subject. GBL and LA approaches enable teachers to leverage on the wealth of information and help them provide accurate feedback to students and improve their teaching quality [17] to gain a better understanding of the learning environment [18]. Thus, the integration of LA and GBL in the course of teaching and learning Mathematics helps improve teaching quality and enhance students' learning skills.

\subsection{The Application of Theory in LA in Mathematics}

However, teacher should apply some learning theory to get the better result. The theory of planned behaviour [1] should be insert because this theory will help teacher to visualise student behaviour and understand students in deep when they use GBL. According to [1] students' behaviour can be planned and predicted based on elements that can influence a person's desire to engage in behaviour. This is because pupils' behaviour in Mathematics will determine the learning opportunities and levels of achievement in Mathematics based on their perception and feelings towards Mathematics. Hence, this theory is suitable to apply in LA because it's allowed teachers to interpret the data to predict both students' achievement and behaviour.

Besides, the application of GBL in LA requires that teachers emphasize the application of cognitive load theory [20]. The application of this theory enables the cognitive load factor of students to be considered in developing GBL applications. Cognitive load is the amount of mental activity that is used by working memory while processing information where the cognitive load during the learning process is at a minimum to enable effective learning [21]. This is because a good and effective learning process occurs when the learning materials used are in line with students' cognitive design [20]. Therefore, if the cognitive load received by a large student exceeds the cognitive level, then the learning process implemented will not achieve its objectives and will fail. Therefore, teachers need to focus on organizing learning information according to students' cognitive needs. So that students can apply their cognitive resources more effectively. 


\section{Conclusions}

Applying LA in Mathematics education brings great benefits that will improve the quality of teaching and learning in classrooms. The use of LA also helps teachers visualise students' progress throughout the lesson. This will in one way or another refine teachers' teaching skills too. LA also allows teachers to gauge students' achievement and predict their dropout rates. These expectations allow teachers to identify students who face learning difficulties and further help them improve to prevent dropouts. LA is also closely related to the quasi-experimental study because it has the potential to report the existing knowledge of students and describe their experiences throughout the learning process [4]. In future, the application of the LA and GBL approaches in Mathematics is an approach that can be explored in-depth to assess its effectiveness to improve students' mastery in Mathematics. This is because the data from GBL approach can be manipulated to help teachers understand students in deep. Teacher also suggested to apply some learning theory like theory of planned behaviour [1] and cognitive load theory [20]. This theory should be injected because it will help teacher to visualise student behaviour and understand students in deep.

\section{References}

[1] Ajzen, I. 1991. The theory of planned behavior. Organizational Behavior and Human

[2] Decision Processes 50: 179-211.

[3] Asselstine, S., Bloom, D., Chercka, A., Clark, A., Elford, S., Lee, D., York, J. (2015). Minecraft in the classroom: Ideas, inspiration, and students projects for teachers. (C. Gallagher, Ed.). San Francisco: Peachpit Press.

[4] Byun, J. \& Joung, E. (2018). Digital game-based learning for K-12 mathematics education: A meta-analysis. School Science and Mathematics 118(3-4): 113-126. https://doi.org/10.1111/ssm.12271

[5] Duzhin, F. \& Gustafsson, A. (2018). Machine Learning-Based App for Self-Evaluation of Teacher-Specific Instructional Style and Tools. Education Sciences 8(1): 7. https://doi.org/10.3390/educsci8010007

[6] Gil-Doménech, D. \& Berbegal-Mirabent, J. (2019). Stimulating students' engagement in mathematics courses in non-STEM academic programmes: A game-based learning. Innovations in Education and Teaching International 56(1): 57-65. doi:10.1080/14703297.2017.1 330159

[7] Huang, S. \& Fang, N. 2013. Computers \& Education Predicting student academic performance in an engineering dynamics course : A comparison of four types of predictive mathematical models. Computers \& Education 61: 133145. doi:10.1016/j.compedu.2012.08.015
[8] Hue, J. P., Kang, I. A. \& Shin, S. S. (2015). A case study of applying learning analytics in general mathematics class. Indian Journal of Science and Technology. doi:10.17485/ijst/2015/v8i21/78382

[9] Kim, D. R., Hue, J. P. \& Shin, S. S. (2016). Application of learning analytics in university mathematics education. Indian Journal of Science and Technology 9(46). doi:10.17485/ijst/2016/v9i46/107193

[10] Lu, O. H. T., Huang, A. Y. Q., Huang, J. C. H., Lin, A. J. Q. \& Yang, S. J. H. 2018. Applying Learning Analytics for the Early Prediction of Students ' Academic Performance in Blended Learning.

[11] Molenaar, I. \& Knoop-van Campen, C. (2018). How Teachers Make Dashboard Information Actionable. IEEE Transactions on Learning Technologies 1382(c): 1-9. doi:10.1109/TLT.2018.2851585

[12] Nguyen, Q., Rienties, B., Giesbers, B., Fournier, H., Canada, C., Kop, R., Ruipérez-valiente, J. A., et al. (2017). Learning Analytics and Educational Data Mining in Practice: A Systematic Literature Review of Empirical Evidence The research questions. Journal of Learning Analytics 17(2): 73-86. doi:10.18608/jla.2016.32.8

[13] Okur, M. \& Aygenc, E. (2018). Video games as teaching and learning tool for environmental and space design. Eurasia Journal of Mathematics, Science and Technology Education 14(3): 977-985. doi:10.12973/ejmste/80932

[14] Outhwaite, L. A., Gulliford, A. \& Pitchford, N. J. 2017. SC. Computers \& Education. doi:10.1016/j.compedu.2017.01. 011

[15] Román-González, M., Pérez-González, J. C., Moreno-León, J. \& Robles, G. (2018). Can computational talent be detected? Predictive validity of the Computational Thinking Test. International Journal of Child-Computer Interaction. doi:10.1016/j.ijcci.2018.06.004

[16] Romero-Zaldivar, V. A., Pardo, A., Burgos, D. \& Delgado Kloos, C. (2012). Monitoring student progress using virtual appliances: A case study. Computers and Education 58(4): 1058-1067. doi:10.1016/j.compedu.2011.12.003

[17] Ruipérez-valiente, J. A., Muñoz-merino, P. J., Leony, D. \& Delgado, C. 2015. Computers in Human Behavior ALAS-KA: A learning analytics extension for better understanding the learning process in the Khan Academy platform 47: 139-148. doi:10.1016/j.chb.2014.07.002

[18] Siemens, G., Dawson, S., \& Lynch, G. (2013). Improving the quality and productivity of the higher education sector: Policy and strategy for systems-level deployment of learning analytics.

[19] Siemens, G. and Baker, R. S. J. (2012). Learning Analytics and Educational Data Mining: Towards Communication and Collaboration. LAK ' 12 Proceedings of the 2nd International Conference on Learning Analytics and Knowledge, $\quad$ pp. 252- 254 https://doi.org/10.1145/2330601.2330661

[20] Steinmaurer, A., Pirker, J. \& Christian, G. 2020. The Challenges of the Digital Transformation in Education 917: 614-625. doi:10.1007/978-3-030-11935-5

[21] Sweller, J., Van Merrienboer, J. J. G., \& Paas, F. G. W. C. 
(1998). "Cognitive architecture and instructional design." Educational Psychology Review, 10 (3), 251-296.

[22] Sweller, J. (2002). "Visualisation and Instructional Design." Australia: University Of New South Wales. 1501 - 1510.

[23] Tokac, U., Novak, E. \& Thompson, C. G. (2019). Effects of game-based learning on students' mathematics achievement: A meta-analysis. Journal of Computer Assisted Learning 35(3): 407-420. doi:10.1111/jcal.12347

[24] Tomkin, J. H., West, M. \& Herman, G. L. (2018). An Improved Grade Point Average, With Applications to CS Undergraduate Education Analytics. ACM Transactions on Computing Education 18(4): 1-16. doi:10.1145/3157086

[25] Vladimir L., U., Jeffrey P., B., Ashok, S., Timothy, K., Alexander, U., Jitendra, S. \& Rama, R. (2019). Smart Learning Analytics: Conceptual Modeling and Agile Engineering 59: 291-301. doi:10.1007/978-3-319-39690-3 